\title{
Reimbursement for reconstruction by tissue transfer-a European comparison
}

\author{
Oliver Lotter ${ }^{1 *}$, William Arthur Townley ${ }^{2}$, Philipp Gonser ${ }^{1}$, Hans-Eberhard Schaller ${ }^{1}$ and Sebastian Hoefert ${ }^{3}$
}

\begin{abstract}
Background: Case payment mechanisms have become the principal means of remunerating hospitals in most developed countries. Our purpose was to analyse the reimbursement for different types of tissue transfer in five European countries.

Methods: We looked at common surgical options for pedicled and free flaps. The recipient site of a flap and the principal diagnosis were systematically modified and processed with national grouper software in order to identify Diagnosis-Related Groups from which the proceeds were derived. The primary data originated from the database of the German Institute for the Hospital Remuneration System as aggregate information. We conducted eight specialist interviews to transfer the available data into clinical practice. Data of real patients were not available and we rather simulated standard patients to avoid dilution of results.

Results: Altogether, payment for pedicled flaps averaged $5933 €$ and was $8517 €$ for free flaps. The comparison of both flap types within a country revealed significant differences in Germany, Austria and Sweden only $(p<0.001)$. Italy has the highest mean proceeds for pedicled flaps, followed by Sweden, Germany, Austria and the UK. This relationship changes for free flaps with Sweden achieving the highest payments. Overall, reimbursement conformity is higher for free flaps.

Conclusions: Most countries have procedure-driven payment systems for flap surgery, which additionally can strongly depend on the diagnosis. Nevertheless the latter does not always justify existing price differences. For the first time, clinical cases in tissue transfer were compared internationally. In today's dynamic world of health care, we should observe other countries' compensation systems to identify ways of improving our own.
\end{abstract}

Keywords: Tissue transfer, Flaps, Reimbursement, Diagnosis-Related Groups, Health care policy, Health services research

\section{Background}

Reimbursement systems for hospitals are very complex and differ between countries. In this context, DiagnosisRelated Group (DRG) is the most common payment system to classify hospital cases into groups with similar use of resources. Fetter and Thompson created it in 1967 at Yale University [1]. In contrast to fee-for-service payments, capitation fees and per-diem payment reimburses, DRG is a fixed-payment system. The introduction of lump sum reimbursement by DRG has led to profound effects on the hospital landscape in the affected

\footnotetext{
* Correspondence: oliver.lotter@freenet.de

${ }^{1}$ Clinic for Plastic, Hand and Reconstructive Surgery, Burn and Trauma Center, Eberhard-Karls-University, Schnarrenbergstrasse 95, 72076 Tuebingen, Germany

Full list of author information is available at the end of the article
}

countries. The aims of increasing efficiency, transparency, standardization and cost reduction are barred in particular by fears of quality loss in medical care and revenue declines. Currently, 20 of 34 member countries of the Organization for Economic Cooperation and Development (OECD) have adopted DRG-based payment systems [2]. All countries we looked at adopted this system.

Defect reconstruction through flaps often implies cost intensive and highly elaborate operative therapies using tremendous resources and requiring special technical prerequisites as well as specific microsurgical skills of the operating team. Such therapies are frequently conducted in a multidisciplinary approach. Since the 1970s, free transfer of vascularized tissue has become the procedure of choice in many cases, because this proceed is often able to solve

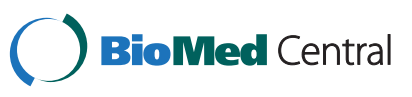


surgical problems more quickly and with less morbidity than traditional techniques [3]. However, increasing concerns about the high cost of such therapies continue to be raised [4]. Furthermore, the difference in pay of the various reconstructive options carries the risk that treatment decisions are influenced monetarily. Overall, these developments lead to an increased utilization of healthcare resources, which must be mastered by national payment systems.

In the following investigation, the German, Austrian, Italian, British and Swedish reimbursement systems are analysed regarding common pedicled and free flaps while considering various underlying diagnosis as well as different recipient regions. Our purpose was to highlight and discuss special characteristics of reimbursement both nationally and internationally. According to our literature review, this study is the first to compare different reimbursement systems according to specific clinical cases in reconstructive plastic surgery.

\section{Methods}

The underlying primary data of our analysis originates from the database of the German Institute for the Hospital Remuneration System of the year 2012 [http://www. g-drg.de/cms/Archiv/Systemjahr_2012_bzw._Datenjahr_ 2010\#sm7]. This database contains aggregate and anonymized data on patients and billing of all German hospitals as well as cost data of selected reference hospitals within the German DRG system (no outpatient services, private inpatient billing or patients within the Employers` Liability Insurance). The aggregated data which is codified by ICD-10- and OPS-Codes (diagnoses and procedures) can only give some information about the localization of flaps but does not allow the identification of a specific flap type. For transfer of the available data into clinical practice, eight specialists in Plastic Surgery with their main activity in Reconstructive Plastic Surgery working at five German, one British and one Italian University Hospital were interviewed. Furthermore, actual versions of known international textbooks were used to identify commonly used flap types with different indications.

Data of real patients were not available nationally or internationally and we refrained from basing our analysis on real patient data of a single institution or a few institutions. However, we expected that some flap operations were performed more frequently than others in our European context, irrespective of personal experience and preferences of decision makers and surgeons in the single hospitals. In this analysis we rather simulated standard patients to avoid irrelevant factors such as comorbidities and complications to dilute the results and drift away from the focus.

We looked at 20 flaps altogether, each 10 pedicled and 10 free flaps with recipient sites on head and neck, trunk (except for the breast), buttocks as well as the upper and lower extremities (Table 1).

In addition to recipient site modification of a flap, the following matrix for the underlying diagnosis was used to discover possible differences in the DRG-assignment: 1. open wounds, 2 . deep lesions with possible co-damage of tendons and muscles, 3. third grade open fractures, 4. infection after operation, 5. osteomyelitis, 6. malignoma, 7. benignoma, 8. full thickness burn injuries. Furthermore, frostbite at hands, feet and nose as well as decubitus ulcers at the head, back, seat area and feet were analysed separately as they are not applicable to all body regions. To simulate different clinical situations, the diagnosis and - if possible - the operative procedure(s) were modified. Each combination of diagnosis and procedure(s) was extended by two additional scenarios (multiple sessions): First, a surgical wound debridement or local excision of pathological tissue was codified in the same setting as the flap surgery. Second, the debridement or local excision was made on day one as a single procedure and repeated five days later together with the flap surgery. This corresponds to a total of 2505 combinations in the 5 different national reimbursement systems (20 flaps $\times 8$ underlying diagnoses $\times 5$ countries $\times 3$ scenarios + frostbite 3 locations $\times 5$ countries $\times 3$ scenarios + decubitus ulcers 4 locations $\times 5$ countries $\times 3$ scenarios).

The diagnoses and procedures were processed to determine the appropriate DRG, using a special grouper software. We applied the German ID Diacos ${ }^{\circledR}$ grouper of Firma ID (Berlin), the official Austrian software package $\mathrm{KDok}^{\oplus}$ and the Italian CMS grouper of Fondazione Medtronic Italia ${ }^{\oplus}$ (Milano) Version 24 [5-8]. In the British system, Healthcare Resource Groups (HRGs) were derived from the HRG4 2012/2013 Local Payment Grouper and

Table 1 Allocation of pedicled and free flaps to different recipient areas

\begin{tabular}{lcc}
\hline \multirow{2}{*}{ Recipient area } & \multicolumn{2}{c}{ Flap type } \\
\cline { 2 - 3 } Head and Neck & Temporofascial flap & Anterolateral thigh flap \\
Trunk & Frontal flap & Free radial forearm flap \\
& Latissimus dorsi flap & Latissimus dorsi flap \\
Buttocks & Gracilis flap & Gracilis flap \\
& Gluteal rotation flap & \\
Upper extremity & Riceps femoris flap & \\
& Radial forearm flap & Anterolateral thigh flap \\
& Groin flap & Lateral arm flap \\
Lower extremity & Gastrocnemius flap & Lerratus fascial flap \\
& Suralis flap & Anterolateral thigh flap \\
\hline
\end{tabular}


the reimbursement was then generated by using the national tariff under Payment by Results (PbR) funding policy [9]. For Sweden the identification of NordDRGs was undertaken by the software of DRG System Development $\mathrm{AB}^{\oplus}$ (Stockholm) [10]. All groupers used were in the actual version of the year 2012.

Each DRG code maps to a relative weight, which leads to the payment amount for a particular hospital visit. Furthermore, thresholds of length of stay were determined. These trimpoints usually serve as adjustment parameters for medical payments concerning so called outliers where the hospitalisation time exceeds or falls below certain limits. For the consistency of data, we assumed a 50 year old male patient without any complications or relevant comorbidities.

Conversion of Swedish Kronor (SEK) and Great Britain Pound (GBP) into Euro $(€)$ was performed according to the mean exchange rates of the year $2011(1 €=9.016$ SEK $=0.871$ GBP) [11].

Purchasing power parities (PPPs) were used to make payments between the countries comparable. These indicate how many money units are necessary to acquire the same quantity and quality of goods and services abroad as inland [12]. One Euro that has been earned in Germany is worth $6.2 \%$ less in Austria, $11.3 \%$ less in Italy, 4.4\% less in the UK and 4.5\% less in Sweden [13].

We used independent sample t-tests to compare the thresholds of length of stay and the reimbursement of the different reconstructive options. The tests indicated significant differences between the reconstructive options if the two-sided $\mathrm{p}$-value was lower than the significance level of $\mathrm{p}=0.002$. We chose this value to keep the familywise error rate for the 25 comparisons that we conducted at a 0.05 level $(0.05 / 25=0.002)$.

A Medline literature research included the keywords [(tissue transfer) or (flaps)] and [(Diagnosis-Related Groups) or (reimbursement) or (costs)] and revealed a total of 354 results (status as of 19.06.2012). Out of these, only 18 articles were relevant for our topic.

This manuscript does not report research which requires approval by ethics committee(s) as no human subjects were involved.

\section{Results}

Altogether, 1,920 combinations of diagnosis and procedure(s) for pedicled and free flaps were simulated in the five DRG-systems.

\section{A. DRGs}

Nine different DRGs for pedicled tissue transfer and 7 for free flaps were defined in Germany. For Austria, 3 and 1 DRGs were found respectively and in Sweden 7 and 6 DRGs. In Italy, both types of tissue transfer revealed 6 DRGs each and in England only one single DRG for both pedicled and free flaps was determined.

\section{B. Length of stay}

The upper threshold of length of stay (uLoS) is the only trimpoint available in all countries of our series and is shown in Table 2. The highest values concerning uLoS for pedicled flaps are found in Sweden in combination with burn injuries as the underlying diagnosis (Mean $[\mathrm{M}]=$ 47 days, Standard Deviation $[\mathrm{SD}]=0$ days), followed by deep lesions, infections and burns $(M=35$ days each, $\mathrm{SD}=0$ days) in Italy. Regarding free flaps, again Sweden shows the highest values in burns $(M=47$ days, $S D=$ 0 days) followed by open wounds and deep lesions in Germany $(M=41$ days, $S D=0$ days). Remarkably, some flaps for defect coverage of the upper extremity result in a mean $\mathrm{uLoS}$ which is much shorter than for the same flaps transplanted to other body regions. As expected, the uLoS in the five countries is generally shorter for pedicled flaps

Table 2 Upper threshold of length of stay (ULoS) in pedicled and free flaps (in days)

\begin{tabular}{|c|c|c|c|c|c|c|c|c|c|c|}
\hline & \multicolumn{2}{|c|}{ D } & \multicolumn{2}{|c|}{ AT } & \multicolumn{2}{|c|}{ I } & \multicolumn{2}{|c|}{ UK } & \multicolumn{2}{|c|}{$S$} \\
\hline & Pedicled & Free & Pedicled & Free & Pedicled & Free & Pedicled & Free & Pedicled & Free \\
\hline Open wounds & 24 & 41 & 14 & 20 & 12 & 12 & 18 & 18 & 10 & 28 \\
\hline Deep lesions & 24 & 41 & 14 & 20 & 35 & 34 & 18 & 18 & 13 & 29 \\
\hline Open fractures & 28 & 29 & 14 & 20 & 23 & 24 & 18 & 18 & 11 & 28 \\
\hline Infection & 25 & 38 & 14 & 20 & 35 & 35 & 18 & 18 & 33 & 33 \\
\hline Osteomyelitis & 21 & 19 & 14 & 20 & 24 & 24 & 18 & 18 & 6 & 27 \\
\hline Malignoma & 19 & 19 & 14 & 20 & 24 & 24 & 18 & 18 & 6 & 27 \\
\hline Benignoma & 21 & 19 & 14 & 20 & 24 & 24 & 18 & 18 & 6 & 27 \\
\hline Burn injuries & 21 & 30 & 21 & 20 & 35 & 35 & 18 & 18 & 47 & 47 \\
\hline Mean & 23 & 30 & 15 & 20 & 27 & 27 & 18 & 18 & 16 & 31 \\
\hline (SD) & $(2,75)$ & $(9,68)$ & $(2,55)$ & (0) & $(7,96)$ & $(7,95)$ & (0) & (0) & $(15,25)$ & $(6,89)$ \\
\hline
\end{tabular}


( $M=20$ days, $S D=9$ days $)$ when compared to free flaps $(\mathrm{M}=25$ days, $\mathrm{SD}=8$ days $)$. Using an independent sample t-test there is a statistically significant difference $(\mathrm{p}<$ 0.001 ) between pedicled and free flaps. When comparing the $\mathrm{uLoS}$ between both flap types within the single countries, Italy and the UK do not reach the significance level $(\mathrm{p}=0.977$ and $\mathrm{p}=1.000)$.

\section{Reimbursement}

The single values of reimbursement for pedicled and free flaps are shown in Figures 1 and 2. Italy has the highest mean proceeds for pedicled flaps $(M=7461 €$, $\mathrm{SD}=3376 €)$, followed by Sweden $(\mathrm{M}=7155 €, \mathrm{SD}=7155 €)$, Germany $(M=5450 €, S D=1898 €)$, Austria $(M=5139 €$, $\mathrm{SD}=761 €)$ and the UK $(\mathrm{M}=4776 €, \mathrm{SD}=0 €)$. This relationship changes for free flaps with Sweden achieving by far the highest reimbursement $(M=11654 €, S D=3003 €)$. Proceeds for pedicled flaps with osteomyelitis in Sweden $(\mathrm{M}=11069 €, \mathrm{SD}=0 €)$, as well as burn injuries of all body regions in Italy $(\mathrm{M}=14968 €, \mathrm{SD}=0 €)$ and Sweden $(\mathrm{M}=17889 €, \mathrm{SD}=0 €)$ are in a five-digit range. For free flaps, this is the case most commonly found in Germany (range $10912 €-15875 €$ ) except for open fractures, osteomyelitis and tumors. Again, Italy shows one of the highest reimburses for free flaps in burns $(M=14968 €, S D=0 €)$ and Sweden has all of its flaps reimbursed by five-digit numbers (range $10045 €-17889 €$ ). Generally, there is only a slight difference between both types of tissue transfer in
Italy. It is noticeable that both flap types in open fractures, osteomyelitis as well as benign and malignant tumors lead to much lower reimbursement in Germany when the recipient site is the upper extremity (all $M=3119 €, S D=0 €$ ) compared to the other body regions. Proceeds in Austria are very constant except for pedicled flaps in burn injuries for which more is paid. In Sweden the type of operation mainly determines the payment and the underlying diagnosis only plays a minor role. In general, proceeds are highest for defect reconstruction after full-thickness burns in all analysed countries.

The mean value of the five countries is $5933 €$ ( $M$ range $2159 €-17554 €, S D=2987 €)$ for pedicled flaps compared to $8517 €$ ( $M$ range $3119 €-17554 €, S D=3600 €$ ) for free tissue transfer. Significantly higher values were paid for free flaps than for pedicled flaps $(\mathrm{p}<0.001)$. The comparison of both flap types within a country revealed significant differences in Germany, Austria and Sweden only $(\mathrm{p}<0.001)$.

\section{Multiple sessions}

When looking at the scenarios of multiple sessions, only Austrian proceeds increased. However this was related to benign and malignant tumors as well as full-thickness burns. Regarding scenario I (surgical wound debridement or local excision in the same setting as the flap surgery) the average increase amounted to $19 \%$ in pedicled and $10 \%$ in free flaps. For scenario II (debridement or local

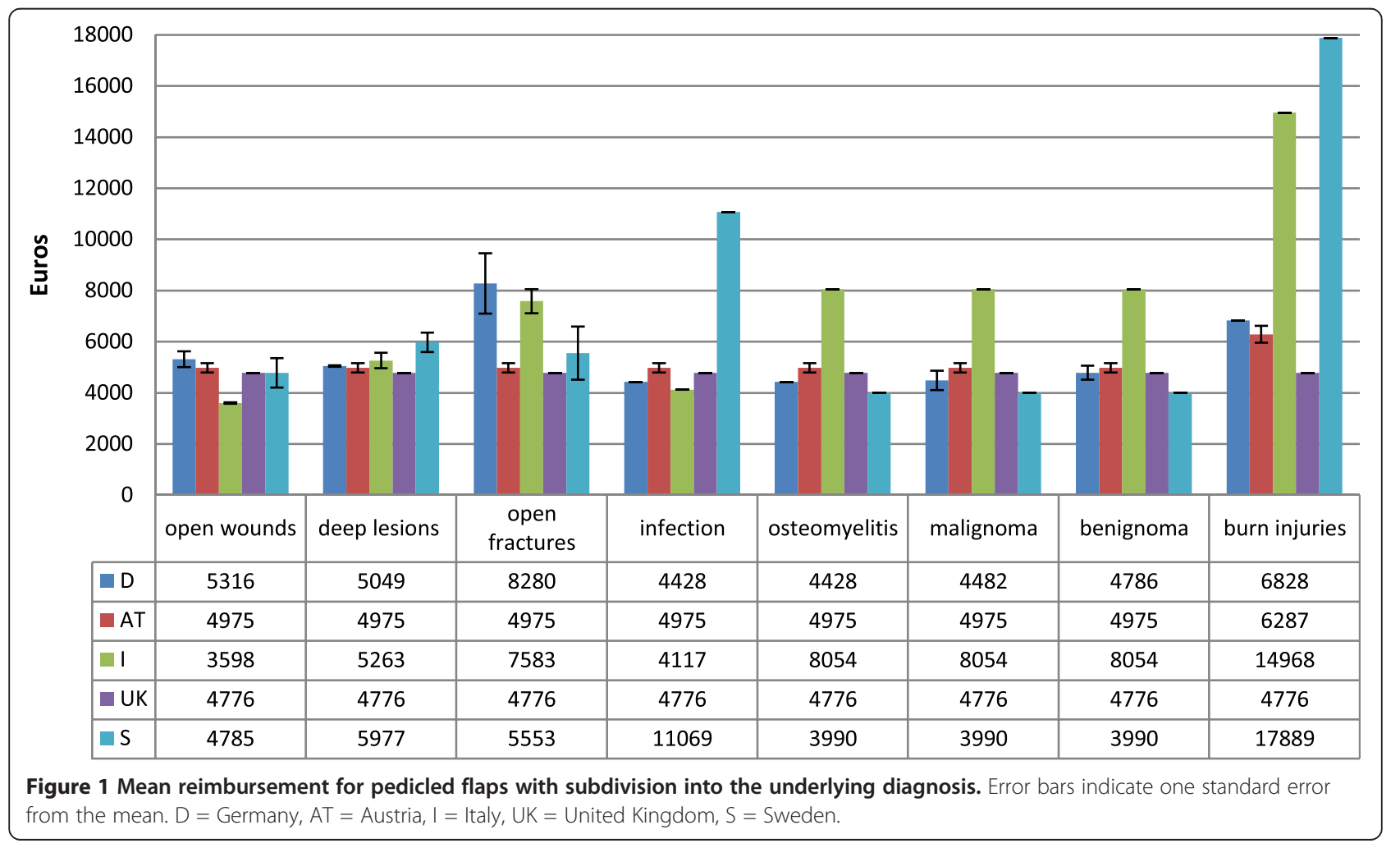




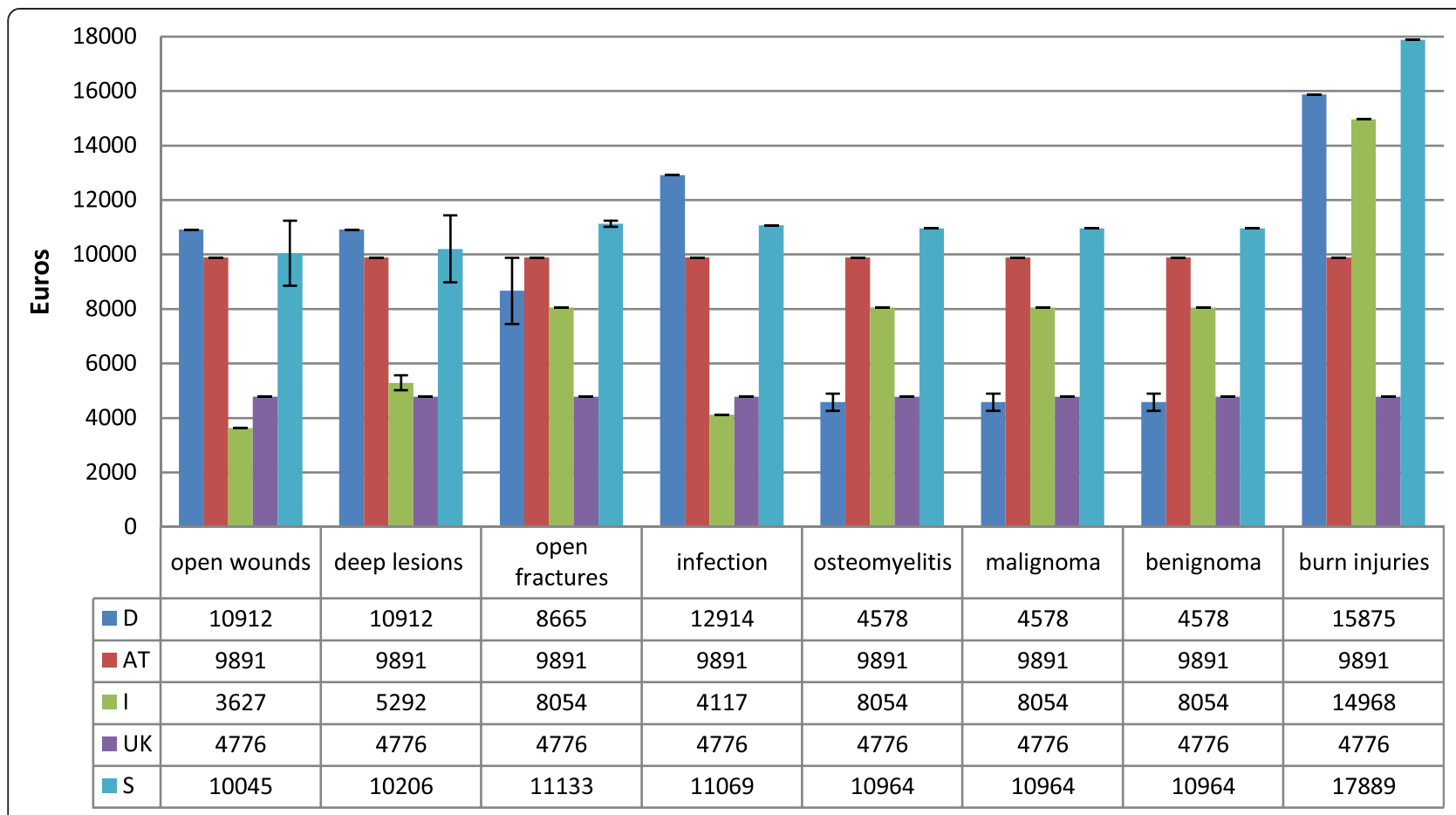

Figure 2 Mean reimbursement for free flaps with subdivision into the underlying diagnosis. Error bars indicate one standard error from the mean. $\mathrm{D}=$ Germany, AT = Austria, I = Italy, UK = United Kingdom, $\mathbf{S}=$ Sweden.

excision on day one and repeated five days later together with the flap surgery), additional proceeds of $36 \%$ or $21 \%$ could be found. The additional temporary wound closure such as Negative Pressure Wound Therapy did not reveal any changes in the definition of DRGs.

\section{E. Special situations}

The reimbursements for frostbite and decubitus ulcers are shown in Table 3 . In Italy and the UK, there is

Table 3 Reimbursement for special situations (in Euros)

\begin{tabular}{cccccc}
\hline \multicolumn{7}{c}{ a) Frostbite } \\
\hline Pedicled flaps & D & AT & I & UK & S \\
Free flaps & 10912 & 9891 & 5708 & 4578 & 12417 \\
Mean & $\mathbf{7 9 6 1}$ & $\mathbf{7 5 2 6}$ & $\mathbf{5 7 0 8}$ & $\mathbf{4 5 7 8}$ & $\mathbf{9 6 0 8}$ \\
(SD) & $\mathbf{( 4 1 7 3 )}$ & $\mathbf{( 3 3 4 5 )}$ & $\mathbf{( 0 )}$ & $\mathbf{( 0 )}$ & $\mathbf{( 3 9 7 3 )}$ \\
\hline \multicolumn{6}{c}{ b) Decubitus ulcers } \\
\hline Pedicled flaps & $\mathbf{D}$ & AT & I & UK & S \\
Free flaps & 8702 & 5160 & 4117 & 4578 & 10601 \\
Mean & $\mathbf{8 7 0 2}$ & $\mathbf{7 5 2 6}$ & $\mathbf{4 1 1 7}$ & $\mathbf{4 5 7 8}$ & $\mathbf{1 1 6 0 8}$ \\
(SD) & $\mathbf{( 0 )}$ & $\mathbf{( 3 3 4 5 )}$ & $\mathbf{( 0 )}$ & $\mathbf{( 0 )}$ & $\mathbf{( 1 4 2 3 )}$ \\
\hline
\end{tabular}

Numbers in brackets indicate one standard error from the mean. $\mathrm{D}=$ Germany, $\mathrm{AT}=$ Austria, $\mathrm{I}=\mathrm{Ital}$, $\mathrm{UK}=$ United Kingdom, $\mathrm{S}=$ Sweden. no difference between the two categories of flaps. The Austrian system shows no variation regarding other underlying diagnoses. A separate DRG for decubitus ulcers is available in Germany, however it does not distinguish between pedicled and free flaps. The highest discrimination can be found in Sweden where different DRGs exist for pedicled and free flaps as well as for decubitus ulcers and frostbites.

\section{F. Single-case comparison and purchasing power parities}

All single-case reimbursments out of the different countries were compared with each other regarding the specific flap used. Altogether 20 different flap types, each 10 pedicled and 10 free flaps, as well as 8 underlying diagnoses were compared from the five above mentioned countries. This led to 1600 direct, single-case comparisons of reimbursement for flaps (Figure 3). Furthermore, Purchasing power parities (PPPs) were used to improve the international comparability of the proceeds. When comparing the native data of pedicled flaps, Italy has most of the highest reimburses, followed by Austria, Sweden, Germany and the UK. This relationship changes when integrating PPPs, placing the UK at the fourth position, thus overtaking Germany. Concerning reimburses of free flaps, Sweden is in the first place, followed by Germany, Austria, then Italy and finally the UK. Austria overtakes Germany when PPPs are applied. 


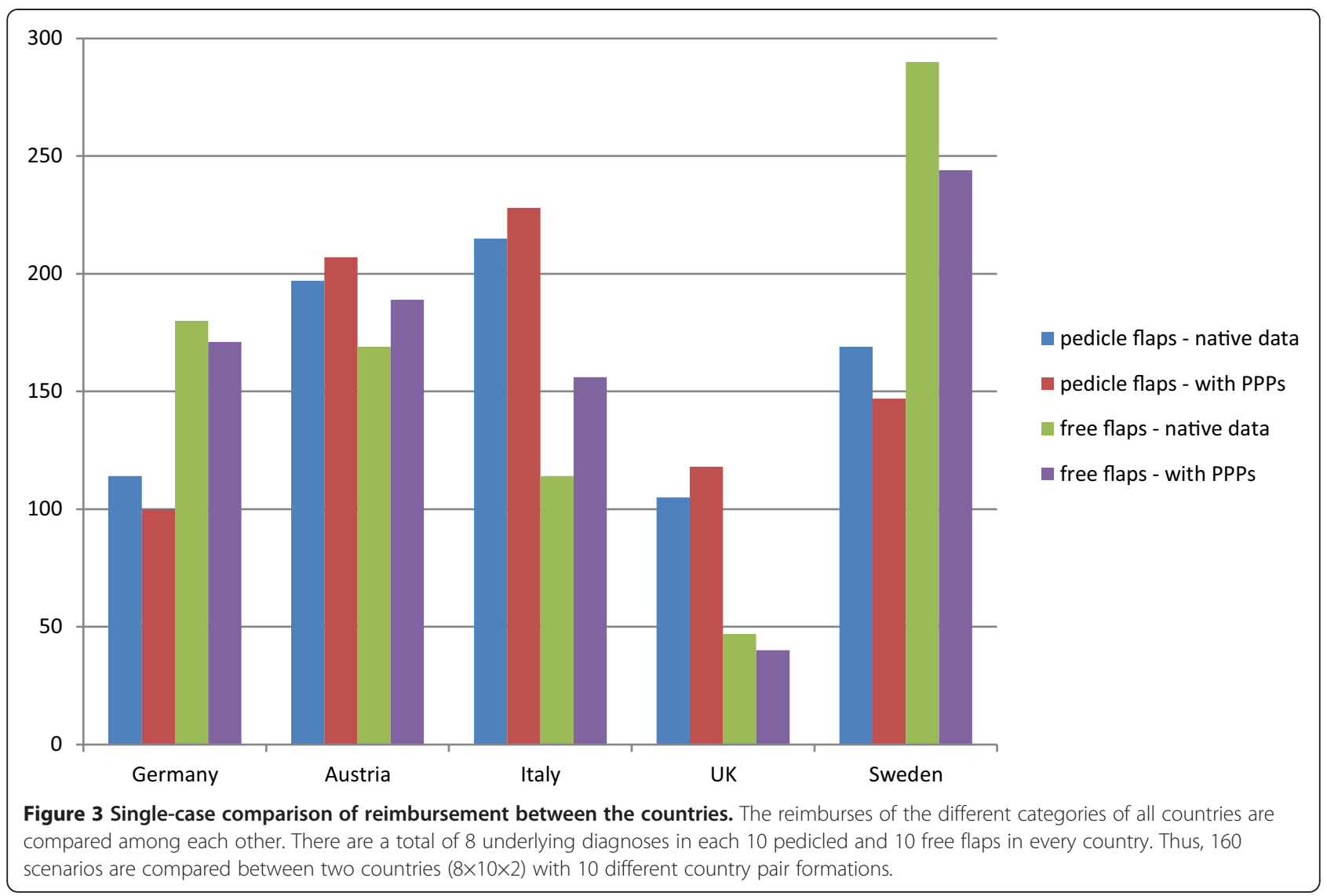

\section{Discussion}

In the present investigation the German, Austrian, Italian, English and Swedish reimbursement systems were compared regarding surgical treatment through pedicled and free flaps with different underlying diagnoses in various body regions. Our aim was to standardize the scenarios to ensure maximal transparency and comparability. Therefore, a predefined algorithm to depict the various tissue transfers both nationally and internationally was applied. We were surprised to find salient contrasts in thresholds of length of stay and reimbursement.

Altogether, we found statistically significant lower values for the upper length of stay (uLoS) for pedicled flaps than for free flaps. In this context, the authors would like to underline the importance of the lower threshold (lLoS), which can only be found in Germany and Austria. Systems with no lLoS have to be critically judged as encouragers of "bloody discharges" and bear the risk of quality loss in medical treatment.

We assumed the reimbursement for free flaps to exceed that of pedicled flaps. This was the case for the average remuneration in Germany (9126€ vs. 5450€), Austria (9891€ vs. $5139 €)$ and Sweden (7036€ vs. $11464 €)$ with statistical significance. Interestingly this discrepancy was found to be much lower in Italy (7461€ vs. $7527 €)$. Furthermore in the UK reimburses for both flap types showed no difference (both $4578 €$ ). For pedicled flaps, the mean value for reimburses of the five countries was $5933 €$ and in contrary $8517 €$ for free tissue transfer. We found no different procedure codes to distinguish free myocutaneous flaps from perforator flaps such as for reconstructive breast surgery in some countries [14]. The authors think this would also make sense for tissue transfer to other body regions than the breast, however, no information about potential cost differences is available so far that could justify such a distinction.

Overall, in reconstructive surgery the British and Austrian systems strongly depend on the procedure(s) and the underlying diagnosis is virtually of no importance. In contrast, grouping in Italy relies on the diagnosis but - as in the UK - there is no adequate discrimination between pedicled and free flaps. The German system is mainly driven by the underlying diagnosis and less by the procedure(s). It has to be questioned whether the leading diagnosis is supposed to have such a strong effect on reimbursement especially in free flap surgery. One exception might be the treatment of burns where the multimodality and complexity of treatment is often higher than in other cases.

Our extensive literature research revealed that most publications concerning flaps were available in the field 
of Head and Neck, Oromaxillofacial and Breast Surgery and only a few were related to other body regions [15-31]. All articles we found were published in medical journals and none in other fields such as health economics or health services research. Interestingly, all but two papers were exclusively analysing the costs of tissue transfer, usually comparing methods of pedicled with free flaps. In this respect, cost-identification analyses were by far the most common type [32]. Differences between pedicled and free tissue transfer were shown to be closely related to length of operative procedure and its subsequent impact on postoperative care including longer stays in the intensive care unit. Mainly in the field of Oromaxillofacial Surgery, other outcome variables showed no statistically significant difference [15-19]. In these studies, the reconstruction type was not significantly associated with overall costs in the majority of cases. We were surprised about these findings, as free tissue transfer requires additional technical equipment (operation microscope), special surgical skills (microsurgical training), mostly longer operation times and higher requirements concerning aftercare and monitoring.

The two papers considering reimbursement were authored in Anglo-American countries with just one analysing two different flap types (pedicled vs. free flaps) and none examining different body regions [22,31]. Furthermore our literature research revealed that all studies based their analysis only on data of one national institution, which by far has no claim to universal validity. For the first time we compared payments internationally avoiding a single-center approach and trying to maximize standardisation between the countries.

One-stage procedures with debridement or tumor resection and tissue transfer during the same hospital stay were considered separately. The higher resource use in these cases compared to reconstruction by flaps only seems logical but reimburses usually remain the same without considering earlier operative procedures during the same stay and reimbursing these cases higher. Unfortunately, up to now there are no cost-identification analyses available to point out this problem.

This study is limited through the focus on only the main diagnosis to create standardised "case vignettes" avoiding comorbidities and complications to ensure comparability and reduce complexity. The selection and distribution of the various flaps was randomly and will strongly depend on the spectrum of a single department performing reconstructive surgery. Furthermore, comparison of international DRG-related data was impaired by numerous variables such as different structural conditions, organization and other factors that cannot be taken into account. The healthcare market is still highly regulated and free market forces are often underrepresented which could lead to falsification [33]. As in most cost analyses, where the primary focus has been identification of costs incurred during the initial hospitalization in which a flap procedure was performed, we also concentrated on reimbursement for the first hospital stay. Consecutive operations were excluded. Last but not least, Purchasing Power Parities allowing international comparison depict the situation of a predefined consumer basket and might not exactly describe the focus of the health care sector.

It would be interesting to include the cost of each scenario to compare the profit of different tissue transfers within and among the countries. However, cost data - if available - often shows less consistency and a large range throughout a country than reimbursement. The mixture of completely different treatment cases under the cover of DRG, resulting in a different consumption of resources is a major barrier for a transparent cost presentation. Therefore we recommend in a first step to exclude the diagnosis from the calculation of reimbursement except for highly elaborate pathologies such as burns for example. In doing so, more emphasis could be put on the operation, which seems to be the main trigger of costs in tissue transfer. In this context, however, monetary reasons are not allowed to motivate the surgeon for or against certain specific therapies.

\section{Conclusions}

Flap surgery is necessarily individualized and specific procedures may be indicated in very different conditions and circumstances, each with a unique pattern of resource use and often independent of the underlying diagnosis. As pointed out in our analysis, this is in contrast to many rigid and inflexible coding systems grouping different flap procedures under only one single procedure code [30]. This leads us to the question whether there should be a higher reimbursement discrimination between various reconstructive options in cases where future in-depth cost analyses have shown obvious discrepancies. For the first time, clinical cases in tissue transfer were compared internationally. The comparison of reimbursement by DRG should be a useful instrument for benchmarking and refinement of a national compensation system while not depending solely on political decisions or country-specific cost data.

\footnotetext{
Abbreviations

CMS: Centers for Medicare and Medicaid Services; DRG: Diagnosis-Related Group; FDA: Food and drug administration; GBP: Great Britain Pound; HCFA: Health care financing administration; HRG: Healthcare resource group; ICD-10: International classification of diseases; LD: Latissimus Dorsi; NHS: National Health Service; OECD: Organization for Economic Cooperation and Development; PbR: Payment by results; PPP: Purchasing power parity; SEK: Swedish Kronor; TRAM: Transverse rectus abdominis muscle; uLoS: Upper Length of Stay.
}

Competing interests

The authors declare that they have no competing interests. 


\section{Authors' contributions}

All authors 1) have made substantial contributions to conception and design, or acquisition of data, or analysis and interpretation of data; 2) have been involved in drafting the manuscript or revising it critically for important intellectual content; and 3) have given final approval of the version to be published. The following list shows the contributions of each author: Study conception and design: OL, SH, HS. Acquisition of data: OL, WAT, PG. Analysis and interpretation of data: WAT, HS, OL. Drafting of manuscript: OL, SH, PG. Critical revision of manuscript and final approval: OL, WAT, HS, SH.

\section{Acknowledgements}

The authors like to express their sincere thanks to Carlo Buniolo from Qbgroup, Padova/Italy and Örjan Leringe from DRG System Development $A B$, Stockholm/Sweden for their support and cooperation in understanding the functional principles of the respective national DRG-systems. Thanks also to Stephan De la Rosa for his professional help with the statistical analyses. We acknowledge support by Deutsche Forschungsgemeinschaft and Open Access Publishing Fund of Tuebingen University.

\section{Author details}

'Clinic for Plastic, Hand and Reconstructive Surgery, Burn and Trauma Center, Eberhard-Karls-University, Schnarrenbergstrasse 95, 72076 Tuebingen, Germany. ${ }^{2}$ Plastic Surgery Department, John Radcliffe Hospital, Oxford OX3 8DU, UK. ${ }^{3}$ Department of Oral and Maxillofacial Surgery, Eberhard-Karls-University, Schnarrenbergstrasse 95, 72076 Tuebingen, Germany.

Received: 11 August 2012 Accepted: 14 August 2014 Published: 24 September 2014

\section{References}

1. Fetter R: Case-Mix Definition by Diagnosis-Related Groups. Med Care Rev 1980, 18:1-53.

2. Organisation for Economic Co-operation and Development: List of OECD Member countries. [http://www.oecd.org/document/58/0,3746,en_2649_ 201185 1889402_1_1_1 1,00.html]

3. Serafin $\bar{D}$, Georgiade $\bar{N} G$, Smith $\mathrm{DH}$ : Comparison of free flaps with pedicled flaps for coverage of defects of the leg or foot. Plast Reconstr Surg 1970, 59:492-499.

4. Pearl RM: An economic analysis of health care reform and its implications for plastic surgery: a five-year perspective. Plast Reconstr Surg 2003, 111:483-484.

5. Institut für das Entgeltsystem im Krankenhaus: G-DRG-System. 2012 [http://www.g-drg.de/cms]

6. ID Diacos Berlin: Online Grouper. 2012 [http://www.clinical-coding.eu/app/ Webgrouper]

7. Bundesministerium für Gesundheit (Federal Department of Health of Austria): Programme für landesgesundheitsfondsfinanzierte Krankenanstalten. [http://www.bmg.gv.at/cms/site/standard.html?channel=CH0719\&doc= CMS1159519039440]

8. Fondazione Medtronic Italia: Software per la simulazione online die DRG. [http://www.e-drg.it]

9. The Information Center for Health and Social Care: HRG4 2012/13 Local Payment Grouper. [http://www.ic.nhs.uk/services/the-casemix-service/ using-this-service/reference/downloads/payment/hrg4-2012-13-localpayment-grouper]

10. DRG System Development AB Sweden: Grouper 2012. [http://www.drgsystem.se]

11. European Central Bank: Statistical Data Warehouse. [http://sdw.ecb.europa.eu/ home.do]

12. Statistisches Bundesamt Deutschland (German Federal Office of Statistics): Verbrauchergeldparitäten (Purchasing Power Parities). [http://www.destatis.de/ jetspeed/portal/cms/Sites/destatis/Internet/DE/Content/Statistiken/Preise/ InternationalerVergleich/Content75/Nerbrauchergeldparitaeten,templateld= renderPrint.psml]

13. Internationaler Vergleich der Verbraucherpreise (International comparison of consumer prices). [https://www.destatis.de/csp/shop/sfg/bpm.html.cms. cBroker.cls?cmspath=struktur,vollanzeige. $. c s p \& \mid D=1025270]$

14. Lotter O, Amr A, Jaminet P, Hoefert S, Schaller HE, Stahl S: Development of DRGs in reconstructive breast surgery. Handchir Mikrochir Plast Chir 2012, 44:112-127.
15. Talesnik A, Markowitz B, Calcaterra T, Ahn C, Shaw W: Cost and outcome of osteocutaneous free-tissue transfer versus pedicledd soft-tissue reconstruction for composite mandibular defects. Plast Reconstr Surg 1996, 97:1167-1178.

16. Smeele LE, Goldstein D, Tsai V, Gullane PJ, Neligan P, Brown DH: Morbidity and cost differences between free flap reconstruction and pedicledd flap reconstruction in oral and oropharyngeal cancer: Matched control study. J Otolaryngol 2006, 35:102-107.

17. Kroll SS, Evans GR, Goldberg D, Wang BG, Reece GP: A comparison of resource costs for head and neck reconstruction with free and pectoralis major flaps. Plast Reconstr Surg 1997, 99:1282-1286.

18. Tsue TT, Desyatnikova SS, Deleyiannis FW, Futran ND, Stack BC, Weymuller EA: Comparison of cost and function in reconstruction of the posterior oral cavity and oropharynx. Free vs pedicled soft tissue transfer. Arch Otolaryngol Head Neck Surg 1997, 123:731-737.

19. Thoma A, Veltri K, Archibald S, Jackson S, Young JE: Microsurgical reconstruction of the through-and-through defect in head and neck cancer: is it worth it? J Reconstr Microsurg 1999, 15:401-408.

20. Funk GF, Hoffman HT, Karnell LH, Ricks JM, Zimmerman MB, Corbae DP. Cost-identification analysis in oral cavity cancer management. Otolaryngol Head Neck Surg 1998, 118:211-220.

21. Arnold DJ, Funk GF, Karnell LH, Chen AH, Hoffman HAT: Laryngeal cancer cost analysis: association of casemix and treatment characteristics with medical charges. Laryngoscope 2000, 110:1-7.

22. McCrory AL, Magnuson JS: Free tissue transfer versus pedicled flap in head and neck reconstruction. Laryngoscope 2002, 112:2161-2165.

23. De Bree R, Reith R, Quak JJ, Uyl-de Groot CA, van Agthoven M, Leemans CR: Free radial forearm flap versus pectoralis major myocutaneous flap reconstruction of oral and oropharyngeal defects: a cost analysis. Clin Otolaryngol 2007, 32:275-582.

24. Katsaros J, Tan E, Robinson DN: Cost-effectiveness of free tissue transfer. Aust N Z J Surg 1988, 58:373-376.

25. Brown MR, McCulloch TM, Funk GF, Graham SM, Hoffman HT: Resource utilization and patient morbidity in head and neck reconstruction. Laryngoscope 1997, 107:1028-1031.

26. Smith DH, Adams JR, Johnston SR, Gordon A, Drummond MF, Bennett CL: A comparative economic analysis of pegylated liposomal doxorubicin versus topotecan in ovarian cancer in the USA and the UK. Ann Oncol 2002, 13:1590-1597.

27. Bennett $\mathrm{CL}$, Armitage JL, LeSage S, Gulati SC, Armitage JO, Gorin NC: Economic analyses of clinical trials in cancer: are they helpful to policy makers? Stem Cells 1994, 12:424-429.

28. Schulman K, Burke J, Drummond M, Davies L, Carlsson P, Gruger J: Resource costing for multinational neurologic clinical trials: methods and results. Health Econ 1998, 7:629-638.

29. Townley WA, Urbanska C, Dunn RLR, Khan U: Costs and coding - Free-flap reconstruction in lower-limb trauma. Injury, Int J Care Injured 2011, 42:381-384.

30. Tong WM, Bazakas A, Hultman CS, Halvorson EG: The transition from pedicled transverse rectus abdominis myocutaneous to perforator flap: what is the cost of opportunity? Ann Plast Surg 2012, 68:489-494

31. Deleyiannis FW, Porter AC: Economic factors affecting head and neck reconstructive microsurgery: the surgeons' and hospital's perspective. Plast Reconstr Surg 2007, 120:157-165.

32. Kezirian EJ, Yueh B: Accuracy of terminology and methodology in economic analyses in otolaryngology. Otolaryngol Head Neck Surg 2001 124:496-502.

33. Vera A: The Industrialisation of the hospital sector by DRG-based prospective payment systems - an interdisciplinary analysis. Gesundheitswesen 2009, 71:10-17.

doi:10.1186/1472-6963-14-427

Cite this article as: Lotter et al:: Reimbursement for reconstruction by tissue transfer-a European comparison. BMC Health Services Research 2014 14:427 